\title{
Tool Wear and Temperatures Analysis While Machining Ti-6Al- 4V in MQCL-MIST Environment
}

\author{
V. V. K. Lakshmi, Department of Mechanical Engineering, GITAM Institute of Technology, Visakhapatnam, India \\ K. V. Subbaiah, Department of Mechanical Engineering, Andhra University, India \\ K. Arun Vikram, Department of Mechanical Engineering, GITAM Institute of Technology, Visakhapatnam, India \\ (iD) https://orcid.org/0000-0001-9720-6539 \\ K. Suresh, Department of Mechanical Engineering, GITAM Institute of Technology, Visakhapatnam, India \\ (iD https://orcid.org/0000-0002-7516-2026 \\ R. D. V. Prasad, Department of Mechanical Engineering, GITAM Institute of Technology, Visakhapatnam, India
}

\begin{abstract}
Sustainable machining of titanium alloys have deficiency of studies on the built-up edges over the cutting tools and temperature correlation in minimum quantity cooling lubrication (MQCL) environment. Researchers focused on experimentation in dry, wet, and MQL (minimum quantity lubrication) conditions to analyze surface finish, cutting forces, and metal removal rates. This work focuses on the study of cutting parameters effects on temperatures and tool wear analysis by consideration of individual response and their optimality basing on signal-to-noise ratios. Efficacy of process parameters on wear of tool and temperatures requires a comprehensive understanding. An elaborated tool wear analysis is carried based on the microscopic flank wear investigations. Machining of Ti-6Al-4V alloy is carried in the environment of MQCL in form of mist using semi-synthetic fluid. Correlation study of tool wear with regard to temperatures is analyzed and regression models generated on tool wear and cutting temperatures individually showed $83 \%$ of goodness-of-fit and correlation regression is $85 \%$.
\end{abstract}

\section{KEYWORDS}

Low Machinability, Mist, MQCL, Sustainability, Temperature, Ti-6Al-4V, Tool Wear

\section{INTRODUCTION}

Metal cutting industries deprive of the cutting tool wear and tear studies for better production efficiencies and optimum costs. Titanium alloys are of low mass with respect to strength and offer high resistance at high temperatures which makes their suitability to aeronautical applications. But they have a limitation of low machinability affecting the cutting tools wear and thereby encompass the application of cutting fluids to reduce the temperatures while machining process and tool-wear 
leading to an overall increase of machining cost. More over the $\alpha-\beta$ alloy (Ti-6Al-4V) is most widely used alloy aggregates up to 60 percent of the total titanium produce. Of late sustainable manufacturing is gaining importance and manufacturing sectors are adopting at all levels - systems, process and design. (David Zelinka \& Bernard Amadei, 2019) in their study tabulated seventeen 'sustainable development goals, (SDG)', targets and effect of their interactions on goals and targets with system dynamic modelling. Of the SDG's listed for manufacturing process health, environment, education, energy and economy are key indicators towards sustainabile production. At process level machining -removal of material is the major manufacturing process (Jayal, Dillon \& Jawahir, 2010), heat energy is produced owing to friction and plastic deformation of work-piece material. (Rahman, Sun, Wang \& Dargusch, 2012) in their work on titanium alloys machining reported the temperature in cutting zone vicinity was as high as $800^{\circ} \mathrm{c}$ during machining of $\beta$-titanium alloy Ti-6Cr-5Mo-5V-4Al. It is imperative to use lubricants in huge quantity to keep the work-piece and cutting tool interaction zone cool. Contrary, such high volume lubricant application results in unsustainable practices such as cost parameter escalation, pollution, machining workmen safety are issues. The use of lubrication in machining has been a threat to environment due to hazardous nature of the lubricant and also the chemical fumes they emanate at elevated temperatures. The main intended functions of lubricants are to reduce heat by carrying it away - coolant, reduce friction -act like a film and flush chips. During high speed machining the other difficulty noticed is lubricant action as film to friction reduction is very poor resulting under performance. Therefore research focus shifted to mechanisms that reduce the lubrication volume as stated by (Dahmus \& Gutowski, 2004) or use of eco friendly lubricants without compromise on quality or costs. Hence a lot of researchers have focused on eco friendly lubricants, nano lubricants, usage of bio oils. Avant-garde techniques developed for application during machining to either reduce cutting-fluids or eliminate them such as dry machining (absence of cutting-fluids), minimum quantity lubrication (MQL), Mist(application of pressure to supply fluid to cutting zone in form of aerosols), use of solids as lubricants, cryogenic cooling and application of nano lubricants. Dry environment though economical and eco friendly poses difficulties while machining of super alloys, hard alloys with poor conductivity resulting in overheating, adherence of chip to tool face, residual stresses and many time necessitates the use of costly coated tungsten carbide cermets, poly-crystalline-diamond 'PCD', and polycrystalline cubic-boron-nitride 'PCBN' (Singh, Dureja, Dogra \& Bhatti,2016). MQL is considered a "green manufacturing" technique as it offers lower pollution, and ensure safety at work place. All these techniques though offer reduced use of fluids have economical and other effects implications on tool life based on the work piece and tool selection combination. Each of the technique has its merits and demerits based on tool, work-piece combination and machining process adopted in addition to process parameters.

The aspect of enhancement of the cutting tool life and reduction of wear attracts researchers to work with titanium making these materials of fastest growing materials applications. Sustainable machining of hard and low-machinability materials like Titanium alloys, have deficiency of studies on the cutting tools wear mechanisms and temperature correlation in Minimum Quantity Cooling lubrication (MQCL) environment. Researchers till date, focused more on experimentation in varying environments dry, wet (flood), and MQL (Minimum quantity Lubrication) conditions to analyze surface finish, cutting forces and metal removal rates. In many studies one of the parameter is kept constant varying other two. Except for few researchers the temperatures are not considered during turning of Ti4A16V alloy. Therefore this paper focus on, study of cutting parameters and their significance varying all parameters simultaneously at four levels on cutting temperatures (tool and work-piece) and tool wear analysis by consideration of individual response and their optimality basing on Signal-to-noise ratios. An elaborated tool wear analysis is carried based on the microscopic flank wear investigations. Machining is carried on Ti-6Al-4V titanium alloy in the environment of minimum quantity cooling and lubrication in form of mist with pre-designed experiments like Taguchi design of experiments. Correlation study of tool wear with regard to temperatures is analyzed for each and every experimental run. 


\subsection{Literature Survey}

Plain turning of titanium alloys, generate continuous helical chips due their properties of less young's modulus and high hardness. Due to the fact that the titanium has high chemical reactivity, it generates fire flames at higher level of process parameters and excessive built-up edges at lower levels of process parameter. The initial research focused on use of non coated tools under flood environment. Later (Ezugwu, Silva, Bonney \& Machado, 2005) carried experimentation on lathe turning using CBN tools and high pressure coolant environment and done comparative analysis of results with that of uncoated tungsten carbide tool. They reported that non-coated WC has exhibited higher tool life in pressurized lubricant delivery system than dry cutting. But CBN tools had lower life in both the environments. They also in yet another study used PVD(Physical vapour coated) tool and effect on roughness of surface under flood and high pressure MQL reported. Surface hardening was observed in flood machining conditions whereas high pressure application improved the process capability. (Jaffery \& Mativenga,2012) in their study employed NbN, AlCrN, Ti6Al coated tools while machining Ti6AL4V work-material and analysed the results in comparison with non coated tool. They reported that coated tools offer good tool life than non coated tools with exception of low cutting speed. The coating has lesser conductivity of heat than Ti alloy hence heat is not carried by tool. More over they observed that coating materials reactivity and solubility with alloy has significant effect on wear.

(Mia, Rahman \& Nikhil, 2017) conducted experimental study varying speed $78,112,156 \mathrm{~mm} / \mathrm{min}$ feed rates at $0.12,0.14 \& 0.16 \mathrm{~mm} / \mathrm{rev}$ at a constant depth-of-cut in dry and pressure applied lubricant delivery environment. The cutting temperatures were reported to be decreased by more than $50 \%$ when machined under pressured jets in comparison to dry environment. The surface quality was also enhanced at high speeds and feeds in pressure jets condition but didn't exhibit the same trend at lesser speeds. They employed two jets one on rake face and another on flank face for better cooling properties.

(Aslantas \& Cicek, 2018) recommends that Titanium (Ti-6Al-4V) to be machined in micro condition if required to have high cutting velocities, various speeds and feeds to have higher surface finish and less cutting forces. But (Narendra, Yogesh, \& Vivek, 2018) reported that micro machining includes the requirement of electromechanical systems which leads to more cost involvement. In addition, the work-piece cannot be treated as homogenous and isotropic in nature. Furthermore, micro machining acts a plough mechanisms rather than chip removal process which is required essentially in alloy grain structures. Hence this work concentrated on macro machining with usage of reduced coolant in form of mist.

(Muthukrishnan, \& Davim, 2011) presented application of coolant on the ceramic insert tool wear study while machining Ti-6Al-4V at average speeds $(45-135 \mathrm{~mm} / \mathrm{min})$ using a ceramic insert. The cutting environment chosen was water soluble coolant and compared the results with dry cutting and reported that diffusion combined attrition is main type of wear mechanism observed followed by attrition wear. In their study (Mustafa, Rahman \& Debashish, 2017) reviewed application of nanofluid MQL in metal machining and they reported use of coolant while cutting aids to slow tool wear process, augments better surface finish, eradicate heat oriented effects and reduce sticking of the work-piece particles on the tool while machining process. So it is immense required to use the cutting fluids for reducing cutting forces, tool wear and temperatures which are not desired in metal machining due to coolant pollution. So the usage of cutting fluids makes the titanium metal machining to be of non-eco-friendly. Apart from it, the cutting fluids influence reduction in temperature fire flames and cutting force generation due to cooling and lubrication effect between tool and rotary work-piece.

(Hegab, Kishawy, Gadallah, Umer \& Deiab, 2018) used Nano multi walled nano-carbon tubes(MWNCT) additives in vegetable oil in MQL environment to enhance the heat capacity during conduction and convective heat transfer modes. They reported that at $120 \mathrm{~mm} / \mathrm{min}$ the surface quality was best. All experiments were carried at constant doc. The chips were segmented and no serrations observed. Only surface roughness and chip morphology was studied and reported. (Bolzonia, RuizNavas, Neubauer, \& Gordo, 2012) and (Abkowitz \& Rowell, 1986) focused study of cutting Ti-6Al$7 \mathrm{Nb}$ alloy and $\mathrm{Ti}-6 \mathrm{Al}-4 \mathrm{~V}$ respectively using powder metallurgy. But the limitation of having less 
fatigue performance using titanium can be further treated with laser surface modification or blending with powder metallurgy can be substituted with hot pressing fallowed by machining, suggested by (Alan, Santos et.al, 2019)

(Bermingham, Palanisamy, Kent \& Dargusch, 2012) conducted experiments in high pressure water based emulsion and cryogenic cooling environment and concluded that the former environment is better in giving tool life than cryogenic-cooling during turning of Ti-6Al-4V. They emphasized position of nozzle through which coolant evicts as most prime parameter of concern. On the other hand,(Niancong, Xiang, Zheng, Huang \& Wang, 2019) utilized MQL and MQCL environment while machining AISI304 steel and reports that as the speed accelerates, the built up edge (BUE) close to the cutting edge of the tool disappears due to diffusion wear mechanism. (Xu, Liu, An \& Chen, 2012) conducted experimetal study while machining alloy titanium under dry and MQL environment with nano coated TiAlN and concluded that coated tools have better tool life than uncoated tool. (Lin, Wang, Yuan, Chen, Wang \& Xiong, 2015) applied water cooling and cryogenic cooling while turning of Ti-6Al-4V alloy at very low depth of cut and compared surface roughness, tool wear. (Pervaiz, Rashid, Deiab \& Nicolescu, 2016) had compared machinability at dry, flood, MQCL environment using vegetable oil while machining of Titanium alloy using an uncoated carbide insert at constant depth of cut $0.8 \mathrm{~mm}$. (Najiha, Rahman \& Yusoff, 2016) \& (Groover, 2002) summarized the advantages and disadvantages of different fluids used in metal cutting process. They straight oils as reported by their studies are excellent as lubricators but very poor coolants and also likely to cause fire, generate smoke at high speeds. Hence there use is limited to low speeds. Whereas on the other extreme the water soluble oils i.e. semi synthetics offer excellent performance as coolants and good corrosion resistance but may cause foaming problem when in flood condition. (Brian, 2020) in his work reiterated that any attempt to improve the process performance depends on variables effect, models and concepts in addition a reliable measuring system in place ensures the objective of waste minimization. Hence selection of factors effecting system, and measuring system accuracy and reliability are also important for system to improve.

Though many researchers have focused on MQL the drawback associated with MQL is the heat transfer rate which is low and hence when cutting "difficult to cut " metals where machining temperatures are high, lubricant may evaporate losing its functionality hence MQL has limited applications. To overcome these limitation in his study (Awal, Mia \& Nikhil, 2017) investigated the temperature, forces and chips while machining under high pressure jet using coated carbide inserts. They used two nozzles one for rake face and the other flank face. The pressure maintained at 80 bar flow rate of the fluid $20000 \mathrm{ml} / \mathrm{s}$. The temperature variation reported by them was in dry cutting $830-1065^{\circ} \mathrm{c}$ deg centigrade and in high pressure coolant use the temperatures dropped by $70 \%$ at shear zone 356-480 deg centigrade. The pressurized air usage added positively to heat transfer rate, thereby reducing temperature and aids to maintain the oil film strength, leading to better lubrication.

Hence application of coolant using minimum quantity cooling \& lubrication (MQCL) in the form of mist (aerosols) has not been focused while machining Ti-6Al-4V varying all the machining parameters and using a water soluble mineral oil. The use of minimum quantity water soluble mineral oil ensures machining environmental friendly and sustainability ensured. At the same time temperature in correlation with tool wear observations were also not reported for clean machining. Hence in this work, tool wear in conjunction with temperatures on tool and work-piece are reported and analyzed as useful information, while machining under water based cutting fluid in form of mist.

\section{EXPERIMENTATION SETUP AND MATERIALS}

Titanium alloy like Ti-6Al-4V has low thermal conductivity and low young's modulus but retain their strengths even at high temperatures. In this current study Titanium alloy viz. Ti-6Al-4V (Grade 5) with diameter of $50 \mathrm{~mm}$ and length $200 \mathrm{~mm}$ is used as work-piece material for study. Table 1 depicts the chemical composition of the chosen alloy. 
Table 1. Chemical composition of Ti-6Al-4V based on weight percent

\begin{tabular}{|c|c|cc|c|}
\hline $\begin{array}{c}\text { Titanium } \\
(\% \mathbf{T i})\end{array}$ & \multicolumn{1}{c|}{$\begin{array}{c}\text { Iron } \\
(\% \mathbf{F e})\end{array}$} & $\begin{array}{c}\text { Vanadium } \\
(\% \mathbf{V})\end{array}$ & $\begin{array}{c}\text { Aluminium } \\
(\% \mathbf{A l})\end{array}$ \\
\hline 89.29 & 0.23 & 4.39 & & 6.01 \\
\hline
\end{tabular}

Cutting tools like Physical vapor deposited Titanium-Aluminium-Nitride (PVD-TiAlN) coated inserts (i.e. KENNAMETAL- CNMG 120408 MS KC5010 grade) are used for plain turning operation on CNC Turn-Mill (TMC-XL-200 of PMK make) center with Fanuc-0i control system depicted in Figure 1.

The choice of coolant is semi synthetics due to advantages offered good cooling effect to lower the temperatures at shear zones, offer rust control and microbial control at high velocities. However as they tend to foam when used in flood condition, judiciously minimum quantity is used (Groover, 2002). Water based coolant of servo $S$ type (i.e. mixture of 1 liter of coolant and 20 liters of water) is taken and with a controlled and determined way of flashing the coolant sprayed on to the tool tip and work-piece interface zone in form of mist with help of a compressor (FERM make-24 liters capacity). A nozzle which has the chamber of mixing coolant and air (5.5 bar pressure) is used for generating MQCL-mist environment shown in (Figure 2). The high pressure ensures a cooled /chilled air water mixture to eject from the nozzle thus ensuring lower friction coefficient aiding chip removal. The methodology of experimentation is as shown in (Figure 3).

Figure 1. CNC Turn-Mill and MQCL setup

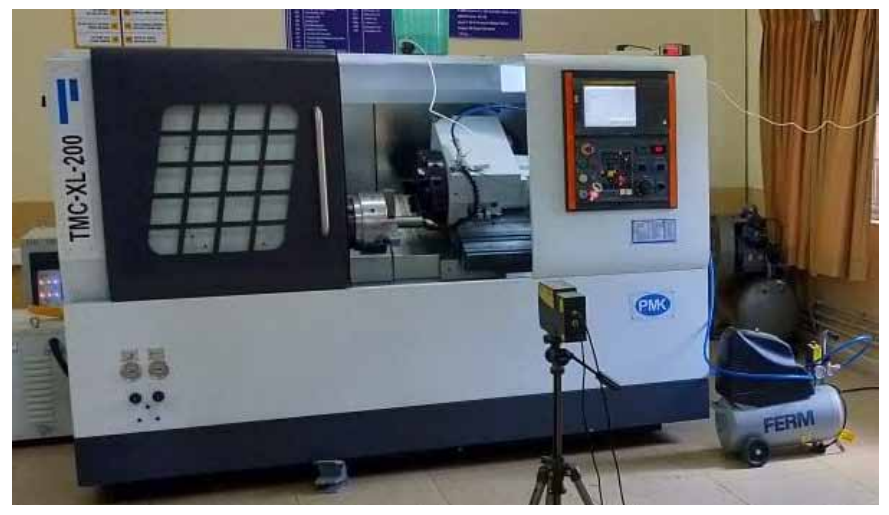

Figure 2. Enlarged view of MIST setup and the nozzle with coolant and air inlets

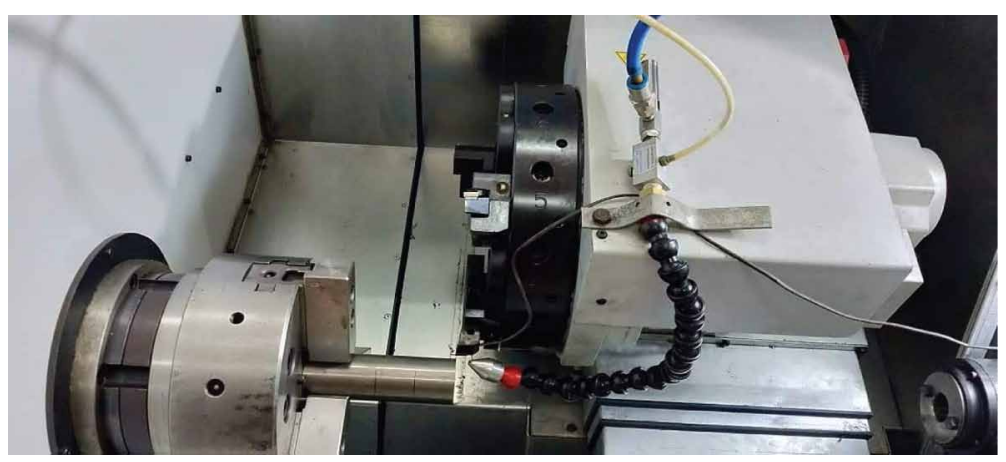


Figure 3. Experimentation methodology

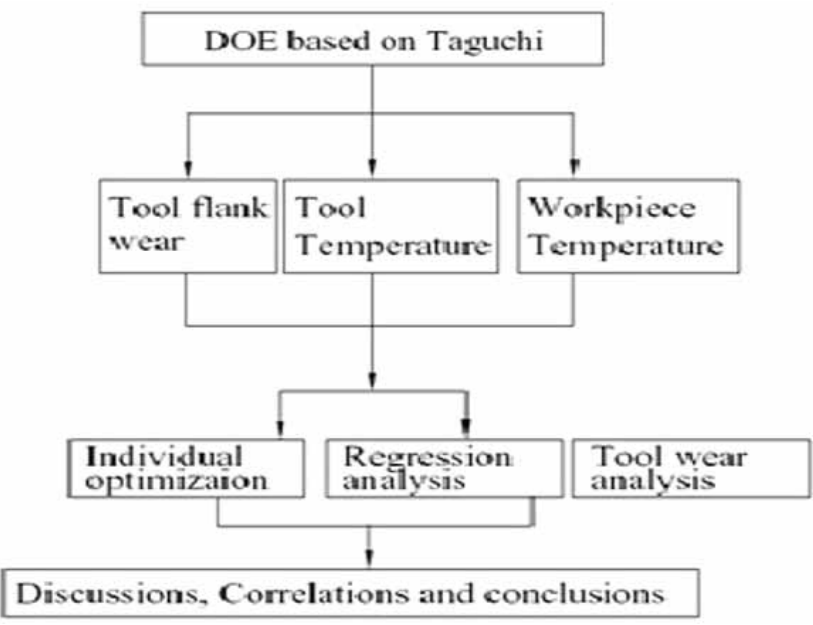

K-type thermocouple with shield is used for online temperature record (Figure 4 (b)). Workpiece temperatures are recorded online using Infrared thermometer, Figure $4 \mathrm{a}$ is a picture of tool wear captured offline using Inverted optical microscope (Leica make with DMILM image analysis software) with a resolution scale of 200 microns and magnification of $10 \mathrm{X}$.

Figure 4. Devices for measuring Temperatures and Tool Wear

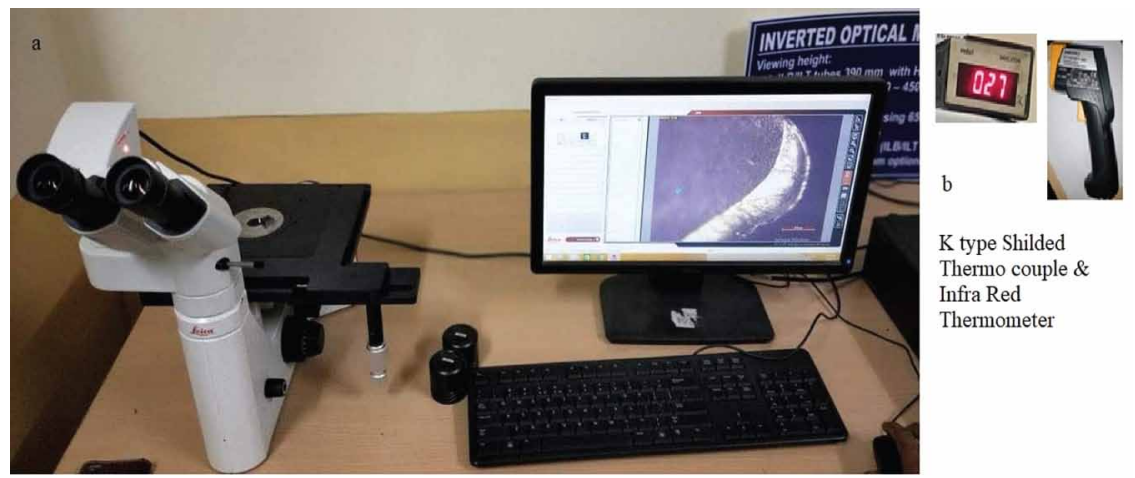

\subsection{Experimental Design and Experimentation}

Taguchi design of experiments (TDOE) utilizing the idea of orthogonal array (OA) is chosen for experimental design, taking in to account parameters like velocity of cut ( $\mathrm{Vc}-\mathrm{m} / \mathrm{min}$ ), tool-feed (Tf$\mathrm{mm} / \mathrm{rev}$ ) and depth of cut (doc-mm) each at four levels thereby generating 16 (L16) combinations with mist condition on the CNC Turn-mill centre as given in Table 2. The tool- wear in form of flank wear (VB- micron), tool temperature (Tt- 0C) and work-piece temperatures (Tw- 0C) are measured as responses. The tool flank wear images are analyzed for flank wear values are recorded (Figure 5-8) all images are after same cutting length, hence in few cases the tool has become blunt due to 
Figure 5. Tool flank wear in experimental run 1,2,3,4 at cutting-speeds $8 \mathrm{~cm} / \mathrm{min}$
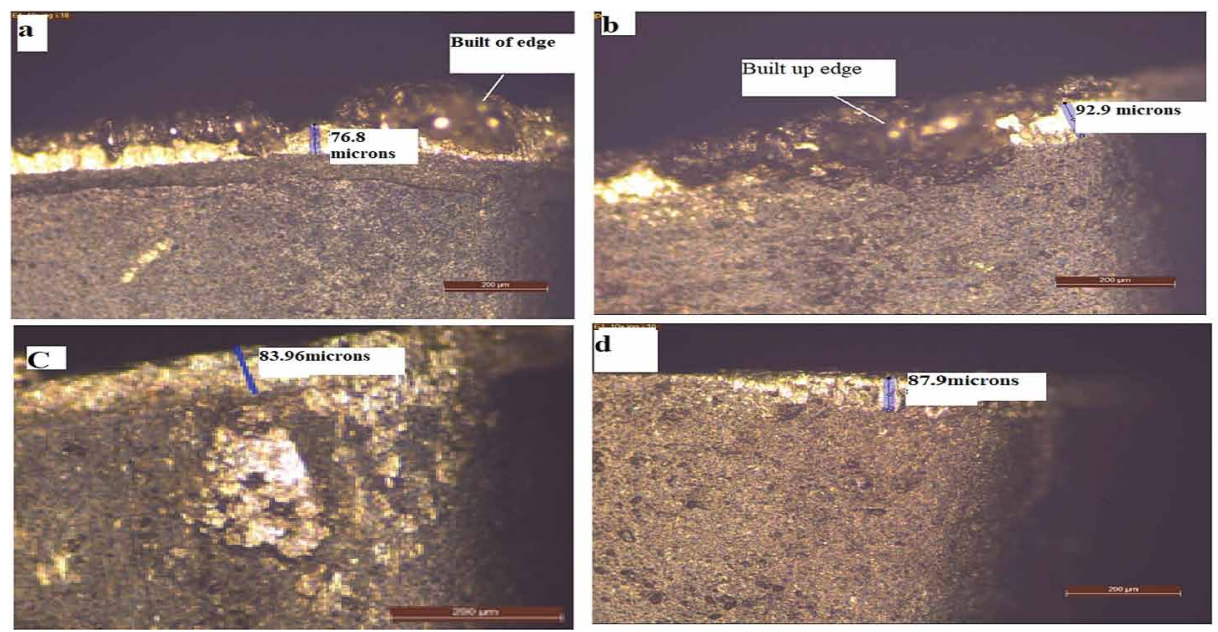

Figure 6. Tool flank wear in experimental run $5,6,7,8$ at cutting-speeds $12 \mathrm{~cm} / \mathrm{min}$
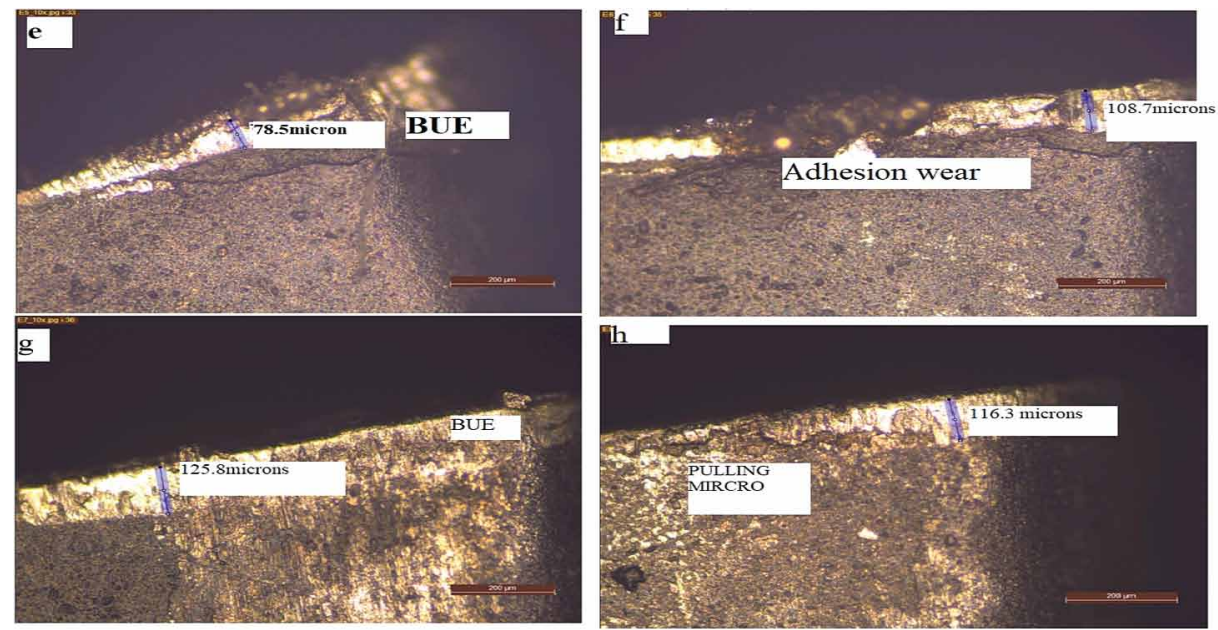

edge morphology change. Ti-6Al-4V (Grade 5) which is classified as alpha-beta alloy work materials are machined with coated PVD-TiAlN carbide inserts in mist environment using designed array of experiments. The choice of tool coating is due to the resistance offered to wear.

The responses like tool temperature, work-piece temperature and tool flank wear are recorded and the Signal-to-noise ratio's (S-N ratios) of the responses are determined based on Equation 1 with an assumption of smaller-is-better option and are recorded and shown in Table 3:

$$
(S N)_{\text {Smaller-is-better }}=-10 \log \left(\frac{1}{n} \sum_{i=1}^{n} y_{i}^{2}\right)
$$


Figure 7 . Tool flank wear in experimental run $9,10,11,12$ at cutting-speeds $16 \mathrm{~cm} / \mathrm{min}$
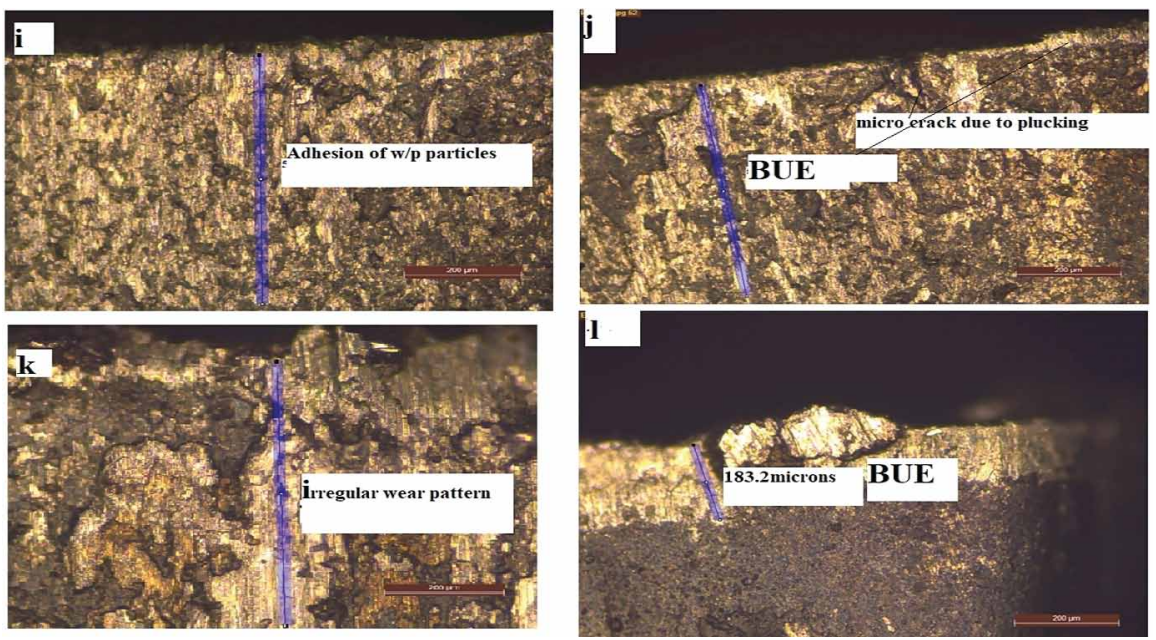

Figure 8 . Tool flank wear in experimental run $13,14,15,16$ at cutting-speeds $20 \mathrm{~cm} / \mathrm{min}$
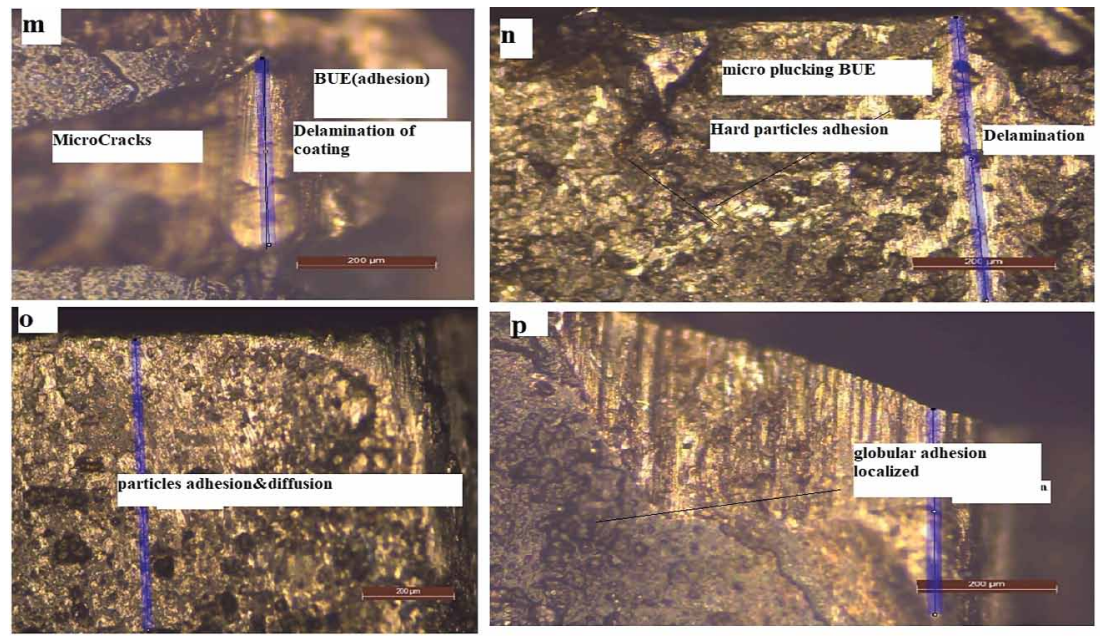

$$
\begin{aligned}
& \eta_{\text {optimum }}=\eta_{\text {op average }}+\sum_{t=1}^{n}\left(\eta_{\text {ideal }}-\eta_{\text {average }}\right) \\
& {\text { Response } \text { optimum }_{\text {espoperage }}}_{10}=\sqrt{10^{ \pm \text {nopt ave }}}
\end{aligned}
$$

The negative sign observed in SN ratio values ensures the selection of the lower better criteria for flank wear, tool and work piece temperature. 
Table 2. Taguchi design of experiments

\begin{tabular}{|c|c|c|c|c|c|c|}
\hline \multirow{2}{*}{$\begin{array}{c}\text { Exp. } \\
\text { No }\end{array}$} & \multicolumn{3}{|c|}{ Machining Parameters } & \multicolumn{3}{|c|}{ Actual Parameters } \\
\hline & $\mathbf{A}$ & B & $\mathbf{C}$ & Vc & f & doc \\
\hline 1 & 1 & 1 & 1 & 80 & 0.05 & 0.25 \\
\hline 2 & 1 & 2 & 2 & 80 & 0.10 & 0.50 \\
\hline 3 & 1 & 3 & 3 & 80 & 0.15 & 0.75 \\
\hline 4 & 1 & 4 & 4 & 80 & 0.20 & 1.00 \\
\hline 5 & 2 & 1 & 2 & 120 & 0.05 & 0.50 \\
\hline 6 & 2 & 2 & 1 & 120 & 0.10 & 0.25 \\
\hline 7 & 2 & 3 & 4 & 120 & 0.15 & 1.00 \\
\hline 8 & 2 & 4 & 3 & 120 & 0.20 & 0.75 \\
\hline 9 & 3 & 1 & 3 & 160 & 0.05 & 0.75 \\
\hline 10 & 3 & 2 & 4 & 160 & 0.10 & 1.00 \\
\hline 11 & 3 & 3 & 1 & 160 & 0.15 & 0.25 \\
\hline 12 & 3 & 4 & 2 & 160 & 0.20 & 0.50 \\
\hline 13 & 4 & 1 & 4 & 200 & 0.05 & 1.00 \\
\hline 14 & 4 & 2 & 3 & 200 & 0.10 & 0.75 \\
\hline 15 & 4 & 3 & 2 & 200 & 0.15 & 0.50 \\
\hline 16 & 4 & 4 & 1 & 200 & 0.20 & 0.25 \\
\hline
\end{tabular}

Cutting velocity (Vc- $\mathrm{m} / \mathrm{min})$

Feed (Tf-mm/rev) Depth of cut (doc-mm)

\section{RESULTS ANALYSIS}

Exact temperature measurements at the cutting zone are tough to perform experimentally, in the current study temperature at the tool tip is perceived as the temperature at heat affected cuttingzone. The variation of the tool-tip temperature at various cutting velocities, depth of cut and feeds is shown in the table. It is trend observed is with elevated parameters of speed, feed and depth of cut increase the cutting temperatures are also increased in MQCL cutting condition. Also as time of machining increases, so does the increase in temperature as reported by (Bermingham, Palanisamy, Kent\& Dargusch, 2012). One possible explanation could be the increase in friction as contact area over a period of time is increased, in the contact zone the friction build up. The temperature rise is dependent on machining duration along with other parameters. Moreover the work piece TiAl3V4 owing to its low thermal conductivity heat accumulation takes place which is observed very high at speeds greater than $160 \mathrm{~mm} / \mathrm{min}$. The temperatures in the current study vary between $45^{\circ} \mathrm{C}$ to $80^{\circ} \mathrm{C}$. These temperatures are close to that reported by (Thrinadh, Rakesh \& Saurav 2020) when they machined with nano MQL. Hence the current choice of cutting environment proves to be giving good results in comparison to nano MQL though the later is complex.It is also much lesser than the dry machining temperatures reported by them $180^{\circ} \mathrm{c}$ at speed of $52 \mathrm{~mm} / \mathrm{min}$, feed $0.2 \mathrm{~mm} / \mathrm{rev}$ and doc $0.5 \mathrm{~mm}$ which is much higher than our current experiment which reported $80 \mathrm{deg}$ at $80 \mathrm{~mm} / \mathrm{min}$ speed. Hence the efficacy of the current work is proved. The low temperatures recorded during the experiments may be due to transformation of the water droplet sprayed at the heat zone into vapor a phase change which improves the heat transfer rate by convection \& conduction in the tool tip rake surface and by convection and radiation in flank face. The oil film acts as lubricant, the phenomena is similar to that observed by (Rosemar et al. 2013) \& (Awal, Mia, Nikhil, 2017). 
Table 3. Observations of tool flank wear and temperatures

\begin{tabular}{|l|l|l|l|l|l|l|}
\hline $\begin{array}{c}\text { Exp. } \\
\text { No. }\end{array}$ & \multicolumn{1}{|c|}{ VB } & \multicolumn{1}{|c|}{$\begin{array}{c}\text { Tt } \\
\left({ }^{\circ} \mathbf{C}\right)\end{array}$} & \multicolumn{1}{|c|}{$\begin{array}{c}\text { Tw } \\
\left({ }^{\mathbf{C}}\right)\end{array}$} & SN Ratio of VB & SN Ratio of Tt & $\begin{array}{c}\text { SN Ratio of } \\
\text { Tw }\end{array}$ \\
\hline 1 & 76.8 & 61.0 & 38.3 & -37.7 & -35.7 & -31.6 \\
\hline 2 & 92.8 & 68.0 & 40.1 & -39.3 & -36.6 & -32.0 \\
\hline 3 & 82.5 & 74.0 & 41.3 & -38.3 & -37.3 & -32.3 \\
\hline 4 & 87.9 & 81.0 & 43.1 & -38.8 & -38.1 & -32.6 \\
\hline 5 & 78.5 & 57.0 & 45.1 & -37.8 & -35.11 & -33.0 \\
\hline 6 & 108.7 & 48.0 & 46.3 & -40.7 & -33.6 & -33.3 \\
\hline 7 & 125.8 & 76.0 & 48.5 & -41.9 & -37.6 & -33.7 \\
\hline 8 & 110.2 & 63.0 & 43.5 & -40.8 & -35.9 & -32.7 \\
\hline 9 & 428.2 & 69.0 & 52.2 & -52.6 & -36.7 & -34.3 \\
\hline 10 & 592.2 & 75.0 & 53.8 & -55.4 & -37.5 & -34.6 \\
\hline 11 & 451.1 & 51.0 & 49.3 & -53.0 & -34.1 & -33.8 \\
\hline 12 & 183.2 & 57.0 & 48.1 & -45.25 & -35.1 & -33.6 \\
\hline 13 & 560.8 & 84.0 & 55.3 & -54.97 & -38.4 & -34.8 \\
\hline 14 & 633.8 & 71.0 & 52.7 & -56.0 & -37.0 & -34.4 \\
\hline 15 & 638.9 & 56.0 & 50.1 & -56.1 & -34.9 & -33.9 \\
\hline 16 & 611.4 & 45.0 & 48.5 & -55.7 & -33.0 & -33.7 \\
\hline
\end{tabular}

Tool flank wear (VB- $\mu \mathrm{m})$

Work-piece temperature(Tw) Tool temperature (Tt)

The tool flank wears observed to be in between $76 \mu \mathrm{m}$ to $638 \mu \mathrm{m}$, while the tool temperatures and work-piece temperatures are observed to be in between 45 to $84 \mathrm{deg} \mathrm{C}$ and 38 to $55 \mathrm{deg} \mathrm{C}$ respectively. The flank wear reported by (Trinadh, Rakesh \& Sourav, 2020) while machining using Nano MQL (MWCNT-Added Rice Bran Oil) and dry cutting at speed $(52 \mathrm{~mm} / \mathrm{min})$, feed $(0.2 \mathrm{~mm} /$ rev), and depth-of-cut $(0.5 \mathrm{~mm})$ with WC insert reported a tool wear of 0.08 and $0.1 \mathrm{~mm}$ under nano MQL and Dry cutting. In current work at $80 \mathrm{~mm} / \mathrm{min}$ speed and $1 \mathrm{~mm}$ doc $0.087 \mathrm{~mm}$ flank wear is observed which is almost same as reported by them but at higher material removal rates. This method proves to be more economical and productive when compared to (Trinadh, Rakesh \& Sourav, 2020) at low speeds as the tool wear progression is also at slow rate as compared to high speeds and dry environment in accordance to that reported by (Bermingham et al, 2015). The wear profiles on flank side as measured from images obtained from microscope using image software are shown in (Figure $5,6,7,8)$. The chips generated in mist conditions are as helical springs segmented chips at speeds of $120 \mathrm{~mm} / \mathrm{min}$ whereas at low speeds and doc the chips are continuous with stringy nature. Similar chip shapes reported by (Awal, Mozammel \& Nikhil, 2017). At high speeds and doc the chips were serrated and also burnt chips and change in color observed for run 10,13,15, 16 (at speeds 160mm/ $\mathrm{min}$, doc $1 \mathrm{~mm}$ ). As speed increased beyond $160 \mathrm{~mm} / \mathrm{min}$ and high doc the chips dis-coloured due to high forces generated, friction was high and hence a chemical reaction in chip occurred due which the chip burnt and deformed. The plastic deformed chip tends to stick more to tool and work-piece. The microscopic image in Figure 7(k) clearly illustrates the flank wear very high also micro cracks, burnt material chipping from edge as well as farther end of flank. This can be due to the chip shearing action as shear force is uneven. The surface profile of the work piece as measured shows 0.61 microns, this may be due to softening of the work piece material, also the hardness value showed a slight decrease which emphasizes the fact that there is change in micro structure. The wear pattern observed 
was combination of coating is delaminated wear as from micro cracks and attrition wear affiliated to formation of prow and adhesion of particles. The uncut chip thickness is also very high due to expose of blunt edge as cutting progressed.

At low feed, the chips were observed as strings. At $120 \mathrm{~m} / \mathrm{min}$ speed at high speeds and doc the chips were broken by the momentum of the jet due to its high velocity. The viscosity of the waterbased oil also helps high coefficient of discharge and as thermal conductivity high better is the cooling ability. Since the mist aerosols are cool as well the water-soluble oil has better thermal conductivity, the convective heat coefficient is good leading to broken chips as opposed to continuous chips in flood lubrication conditions (Nandy, Gowrishankar \& Paul, 2009). Since the pressure is maintained the jet aids to penetrate the blanket of vapor of water formed due to high heat. And also the pressure aids in improving the convective heat transfer rates therefore cutting speeds of $120 \mathrm{~mm} / \mathrm{min}$ may be good in this environment as observed. For run 11 (Figure $7(\mathrm{k})$ ), at $160 \mathrm{~mm} / \mathrm{min}$ at low doc for initial $40 \mathrm{~mm}$ length of cut the chips we continuous helical strings, as aerosols hit the tool \& work piece interface they aid in breaking also.

From the tool wear profile beyond we can conclude that the adhered material was chipped off and a macro crack observed. For speeds $200 \mathrm{~m} / \mathrm{min}$ it was observed that in MQCL condition also the tool life is very less at high depth of cuts. After initial cut for first few seconds sparks were observed, chips were burnt due to chemical reaction as the heat generated is high and aerosols were not enough to remove the heat generated. Speeds beyond $160 \mathrm{~mm} / \mathrm{min}$ the tool life is significantly less and burnt chips were observed after initial $40 \mathrm{~mm}$ length was machined when feed rate is high.

\subsection{Individual Optimality}

The SN ratios of the responses determined using Equation1 and tabulated in Table 4 are further used to determine the individual optimality using Equations 2-3 (Groover, 2002) in Figure 3 and is shown

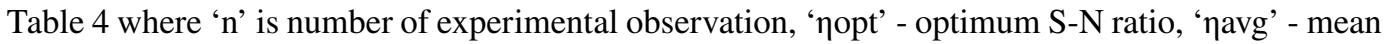
$\mathrm{SN}$ ratio, 'pideal' - At S-N ratio parameter the ideal level.

Table 4. Individual optimal results of variables of process under consideration

\begin{tabular}{|c|c|c|c|c|}
\hline \multirow{2}{*}{ Responses } & \multicolumn{3}{|c|}{ Minimum-Value Combinations } & \multirow[t]{2}{*}{ Optimal-Response } \\
\hline & Vc & Tf & Doc & \\
\hline Tool flank wear & 80 & 0.20 & 0.50 & $57.9(\mu \mathrm{m})$ \\
\hline Tool Temperature & 120 & 0.20 & 0.25 & $45.3\left({ }^{\circ} \mathrm{C}\right)$ \\
\hline Work-piece Temperature & 80 & 0.20 & 0.25 & $38.1\left({ }^{\circ} \mathrm{C}\right)$ \\
\hline
\end{tabular}

The plots of the S-N ratios for various parameters on individual outputs are are shown in (Figure $9(\mathrm{a}, \mathrm{b}, \mathrm{c}))$ and the highest among each group is taken as their ideal $\mathrm{SN}$ ratio. The individual optimal data reveals that, machining at low process parameters in case of hard to machine materials like Ti-6Al-4V generates better responses due to less frictional coefficient and vibrations due to less shearing, which is reduced due to cooling and lubrication of the coolant. The optimal values found as $57.9 \mu \mathrm{m}, 45.3$ $\operatorname{deg} \mathrm{C}$ and $38.1 \mathrm{deg} \mathrm{C}$ for tool flank wear, tool temperature and work-piece temperature respectively. The optimal parameters influencing the response like tool wear and work-piece temperatures are speed of cut followed by depth of cut which enlightens that the relativity among the tool and work-piece that are to be controlled. On the other side, the optimal parameters influencing the tool temperatures are depth of cut followed by cutting speed which shows the shearing of chip from hard to machine work-piece material and its influence on tool surface geometry for controlling the tool life. 


\subsection{Regression Modeling}

Regression analysis and modeling universally accepted method to predict the general behavior of response with respect to parameters modeled under constraints, which aids in selection of parameters at non tested levels also for response under consideration. The surface response parameters in machining can be derived from the experimental data by using the following relations:

Response Toolwear $_{\mathrm{i}}=\mathrm{C} * \mathrm{~V}_{\mathrm{c}} \mathrm{a} * \mathrm{~T}_{\mathrm{f}} \mathrm{b} *$ doce

where $\mathrm{C}$,a,b,e are model coefficients to be estimated from experimental values. The exponential equation form of output is transformed to linear model of second order via logarithmic function as shown in Table 5 and the residual value plots for obtained regression equations are shown in (Figure $10(\mathrm{a}, \mathrm{b}, \mathrm{c}, \mathrm{d}))$.

The regression correlation between the tool flank wear with process parameters and temperatures are closely correlated with a goodness-of-fit of $85.7 \%$, as tabulated in Table 5 and the residual plot (Figure 10(d)). The correlation regression equation confirms the temperatures to be more dominant than the process parameters in generating the tool flank wear. This correlation reveals that the effect of process variables under study influence the temperatures generated in the work-piece material \& tool, as result of shearing action and thereby influencing tool wear and built-up-edge (BUE).]

\subsection{Observations and Discussions}

During the metal removing process by coated carbide tool for Ti-6Al-4V alloy, the significant wear mechanism near the tool \& work-piece interface zone is a combination of diffusive $\&$ abrasive wear machining titanium alloys when using metallic tools is reported by (Rosemar, Álisson, Emmanuel, John \& Wisely, 2013). From (Figures 5 to 8 ) it is observed that in speeds beyond $160 \mathrm{~mm} / \mathrm{min}$ the coating delaminating and galling effect on the tool. For larger cutting velocities, the flank portion wear on the tool and temperatures noticed to be at the maximum which is the reflection of the hardness of

Figure 9. S-N ratios of parameters on a) tool-wear b) tool temperature c) work-piece temperature
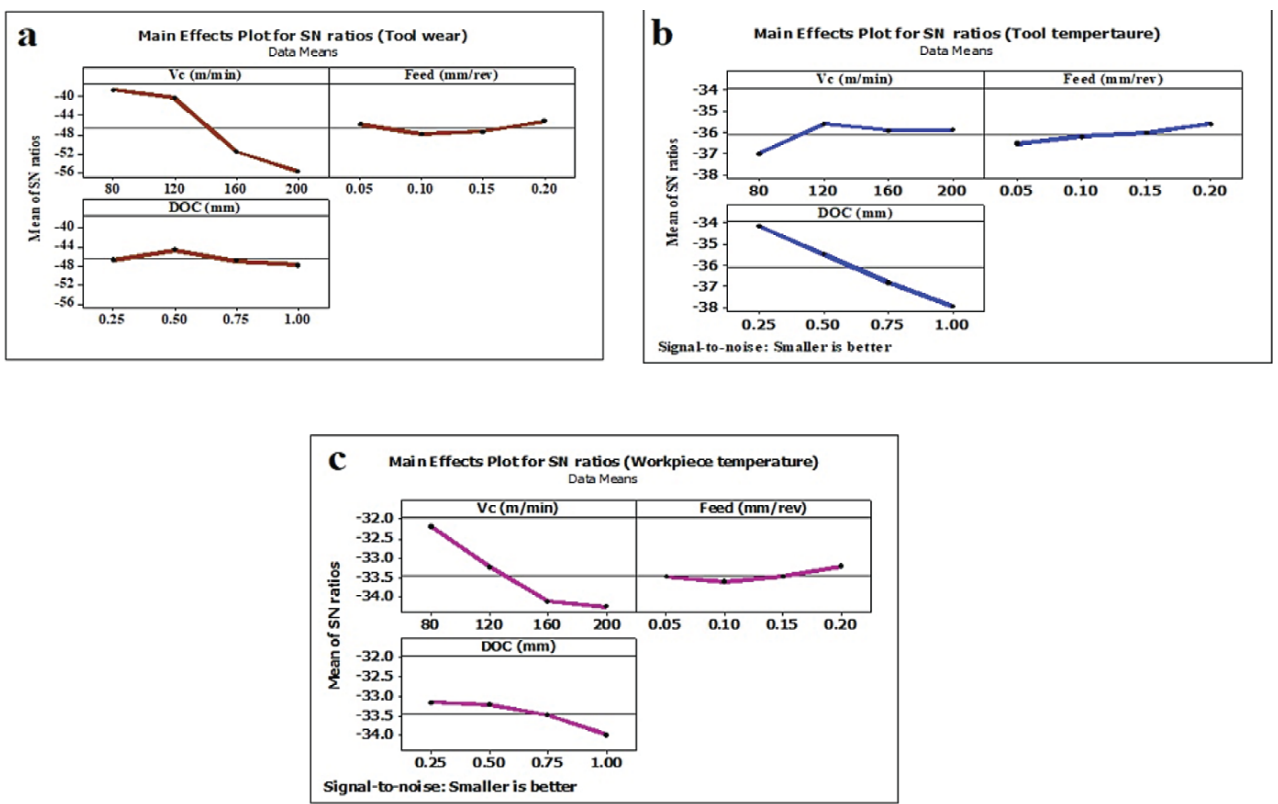
Figure 10. Residual Plot for a) tool wear b) tool temperature c) Correlation of tool-temperature and flankwear
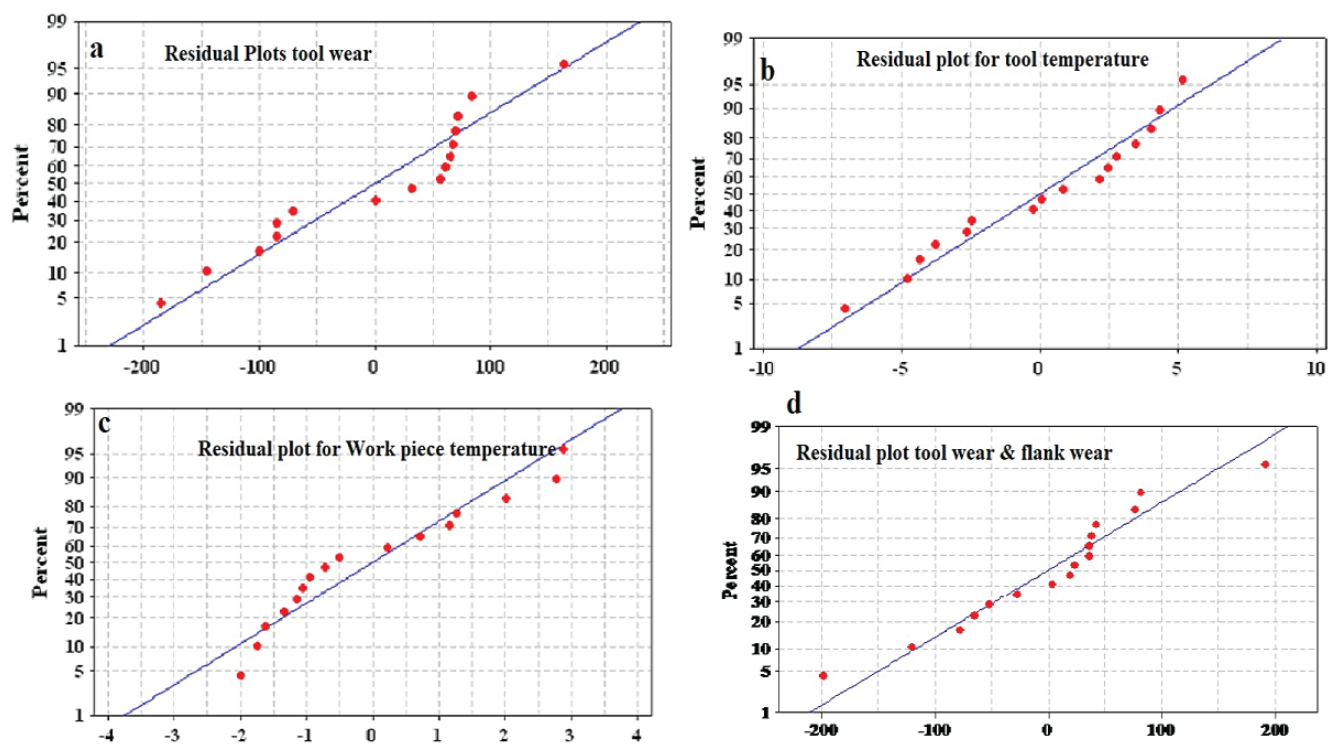

Table 5. Regression models generated while machining Ti-6Al-4V in mist conditions

\begin{tabular}{|c|c|c|}
\hline $\begin{array}{l}\text { Mist MQCL } \\
\text { Environment }\end{array}$ & Second Order Linear Order Model & $\begin{array}{l}\text { Goodness of } \\
\text { Fit }\left(\mathbf{R}^{2}\right)\end{array}$ \\
\hline \multicolumn{3}{|c|}{ For Tool flank wear (VB) } \\
\hline & $\begin{array}{l}58.17-3.01644 * \mathrm{Vc}+3388 * \mathrm{f}-396.51 * \mathrm{doc}+0.0276172 * \mathrm{Vc} * \mathrm{Vc}+366.6 * \mathrm{doc}^{*} \mathrm{doc} \\
-14720 * \mathrm{f} * \mathrm{f}\end{array}$ & $83.2 \%$ \\
\hline \multicolumn{3}{|c|}{ For Tool temperature $(T t)$} \\
\hline & $84.65-0.52875 * \mathrm{Vc}-27.5 * \mathrm{f}+29.7 *$ doc $+0.00171875 * \mathrm{~V} c * \mathrm{Vc}+6 *$ doc $*$ doc $-50 * \mathrm{f} * \mathrm{f}$ & $89.9 \%$ \\
\hline \multicolumn{3}{|c|}{ For Work-piece temperature (Tw) } \\
\hline & $\begin{array}{l}20.5275+0.284937 * \mathrm{Vc}+36.6 * \mathrm{f}-6.38 * \text { doc }-0.000679687 * \mathrm{Vc} * \mathrm{Vc}+10 * \text { doc } * \text { doc } \\
-200 * \mathrm{f} * \mathrm{f}\end{array}$ & $89.7 \%$ \\
\hline \multicolumn{3}{|c|}{ For Tool flank wear correlation with temperatures } \\
\hline & $\begin{array}{l}4834.53-32.2655 * \mathrm{Vc}+632.177 * \mathrm{f}-183.684 * \mathrm{doc}+58.6545 * \mathrm{Tt}- \\
229.398 * \mathrm{Tw}+0.105759 * \mathrm{Vc} * \mathrm{Vc}+489.577 * \mathrm{doc} * \mathrm{doc}+788.43 * \mathrm{f} * \mathrm{f}- \\
0.637086 * \mathrm{Tt} * \mathrm{Tt}+3.23003 * \mathrm{Tw} * \mathrm{Tw}\end{array}$ & $85.7 \%$ \\
\hline
\end{tabular}

the work-piece material and its low-machinability. On the other hand, work-piece material which is very hard to machine is expected to show much higher temperatures from literature, but it was not so and is due to the MQCL effect the aerosols sprayed in the form of mist and water based fluid whose latent- heat of absorbtion is more. This phenomena can be explained by the fact that the pressure air lubricant mixture could penetrate through the vapor formed by the water phase change due to heat at shear zone thereby cooling the work-piece and also forming a lubricating film (Ezugwu et al 2005).

In this study, the formation of built-up-edge is been observed at lower cutting velocities in combination with lower depth of cuts (i.e. experiments 1,2,5 and 6) in (Figures 5(a, b), 6(e, f)) which is due to sticking of abrasion wear of work-piece material on to the heated coated tool. But as the 
depth of cuts increased (i.e. experiments 3, 4, 7 and 8(Figures 5(c, d),6(g, h)) the abrasion which increased due to more shearing action of the work-piece material, fell apart due to an increase in temperatures (tool \& work-piece).

At cutting velocity (like $160 \mathrm{~m} / \mathrm{min}$ ), the lower depth of cuts (like experiments 11 and 12) engraved correspondingly lesser tool flank wear probably due to the formation of $\mathrm{Al}_{2} \mathrm{O}_{3}$ as lubricating layer helped in lower tool wear process (Sharif, Rahim 2007) when compared with higher cutting velocities but the abrasion wear of the material left on the tool in the form of chipping due to the tool heated surface (Figure 7(k, l)). On the other hand at higher depth of cuts (like experiments 9 and 10 (Figure $7(\mathrm{i}, \mathrm{j})$ ) due to large shearing between tool \& work-piece, burning of the tool flank started to emerge and hereby raising tool flank wear and temperatures.

At higher cutting velocities, in context with a higher depth of cuts (i.e. experiments 13 and 14, Figure $8(\mathrm{~m}, \mathrm{n}))$ the fire flames, tool flank burning and change in colour of the chip are observed which may be due to high penetration of tool into high rotating hard material generating high friction, temperatures and also flank wear. But in experiments 15 and 16 (Figure 8(o,p) in conjunction with a smaller depth of cuts, the fire sparkles observed due to the built-up edge which was thrown as sparkles as it has been melted due to high-temperature generation and in addition, there was no change in colour the chip as the tool has less penetration into work-piece hence no burning.

Overall, at higher feed rates and lower depth of cuts, the built-up-edges got wiped of easily due to the presence of mist sprayed on to the tool and showed lesser tool flank wear, the mist acted as chip wiper and also lubricant combined with cooling effect as evident from the temperatures which are low for both work piece and tool tip. But as the cutting velocities, feed and depth of cuts ascended, it can be observed no built-up-edge due to abrasion due to increase in temperatures on both tool and workpiece, while filaments of chipping of work-piece material can be seen due to surface temperatures.

\section{CONCLUSION}

This work investigated the metal machining and the performance of process parameters while machining Ti-6Al-4V with MQCL conditions in generating the responses like tool wear and temperatures. Based on the experimental values, models \& observations during metal alloy cutting process under MQCL MIST environment, the following conclusions and inferences can be drawn:

- From the experimental recordings, it can be inferred that the MQCL in form of mist is better suitable for machining of hard alloys at low to moderate cutting velocities in providing cooling effect as well as lubrication function by the water based synthetic lubricant;

- The cutting velocity reflects to be most effective parameter in generating responses on tool flank wear and work-piece temperature, while depth of cut acts as the most effective process parameter in determining tool temperatures which is due to penetration and shearing of material of tool and work-piece respectively;

- During low cutting speeds with low feeds and depth of cuts, the BUE near the cutting edge appeared due to low machinability of material causing abrasive wear. While on the other hand, at higher feeds and depth of cuts- the built-up edge adhesives fell off due to diffusion wear;

- The results of tool wear and tool temperature are compared to published results with nano MQL and are in closely accordance at level one speeds and all levels of doc and feed rates. This reinforces that MQCL-mist is potentially a better lubricating technique owing to low cost than nano MQCL which is complex process when compared. The tool wear rate was reduced by $20 \%$ and tool temperatures by $25 \%$ when compared to dry machining and flood machining at $80 \mathrm{~m} /$ min speed and all levels of doc;

- The results are individually optimized using Signal-to-noise ratios. The experimental verification resulted with the regression models constructed keeping tool wear and temperatures as objectives 
shown prediction errors to be of $2.15 \%, 5.15 \%$ and $4.38 \%$ VB (microns), Tool temperature (degree) and work-piece temperature (degree) respectively;

- At the high cutting velocities like $200 \mathrm{~m} / \mathrm{min}$, the helical chip were broken due to speedy interaction between tool and hard work-piece and on the other hand, higher fire sparks were observed at higher depths, but fire sparkles were observed at smaller depth of cuts due to built-up-edge melting;

- Beyond cutting speeds of $160 \mathrm{~mm} / \mathrm{min}$ in MQCL environment the tool life is very less and tool coating is completely removed by adhesive particles on the tool and later melts of the same due to heat generated. The chips also are burnt indicating a chemical reaction. Hence for MQCL application speeds below $160 \mathrm{~m} / \mathrm{min}$ are recommended for PVD coated carbide tool.

\section{ACKNOWLEDGMENT}

The authors thank 'Science and Engineering Research Board (SERB)' under 'Department of Science and Technology' with File no: EEQ/2016/000395 for providing financial support for procuring machine tool. 


\section{REFERENCES}

Abkowitz, S., \& Rowell, D. (1986). Superior fatigue properties for blended elemental P/M Ti-6Al-4V. JOM, 38(8), 36-39. doi:10.1007/BF03257786

Aslantas, K., \& Cicek, A. (2018). High speed turning of Ti-6Al-4V in micro cutting conditions. Procedia CIRP, 77, 58-61.

Bermingham, M. J., Palanisamy, S., Kent, D., \& Dargusch, M. S. (2012). A comparison of cryogenic and high pressure emulsion cooling technologies on tool life and chip morphology in Ti-6Al-4V cutting. Journal of Materials Processing Technology, 212(4), 752-765. doi:10.1016/j.jmatprotec.2011.10.027

Bhople, N., Khairnar, Y., \& Divre, V. (2018). A Study On Phenomena Which Differentiate Micromachining From Macromachining. IOSR Journal of Mechanical and Civil Engineering, 4, 75-78.

Bolzonia, L., Ruiz-Navas, E. M., Neubauer, E., \& Gordo, E. (2012). Mechanical properties and microstructural evolution of vacuum hot-pressed titanium and Ti-6Al-7Nb alloy. Journal of the Mechanical Behavior of Biomedical Materials, 9, 91-99. doi:10.1016/j.jmbbm.2012.01.015 PMID:22498287

Dahmus, J. B., \& Gutowski, T. G. (2004). An environmental analysis of machining. ASME International Mechanical Engineering Congress and RD \& D Expo, 1-10.

dos Santos, A., Campanelli, L. C., da Silva, P. S. C. P., Vilar, R., Martins de Almeida, M. A., Kuznetsov, A., Achete, C. A., \& Bolfarini, C. (2019). Influence of a Femtosecond Laser Surface Modification on the Fatigue Behavior of Ti-6Al-4V ELI Alloy. Materials Research, 22(4), e20190118. Advance online publication. doi:10.1590/1980-5373-mr-2019-0118

Ezugwu, E. O., Da Silva, R. B., Bonney, J., \& Machado, A. R. (2005). Evaluation of the performance of CBN tools when turning Ti-6Al-4V alloy with high pressure coolant supplies. International Journal of Machine Tools \& Manufacture, 45(9), 1009-1014. doi:10.1016/j.ijmachtools.2004.11.027

Gall, B. J. (2020). Measurement System Analysis and System Thinking in Six Sigma: How They Relate an How to Use Them. International Journal of System Dynamics Applications, 9(1), 44-62. doi:10.4018/IJSDA.2020010103

Groover, M. P. (2002). Solutions manual: fundamentals of modern manufacturing. Wiley.

Hegab, H., Kishawy, H. A., Gadallah, M. H., Umer, U., \& Deiab, I. (2018). On machining of Ti-6Al-4V using multi-walled carbon nanotubes-based nano-fluid under minimum quantity lubrication. International Journal of Advanced Manufacturing Technology, 97(5-8), 1593-160. doi:10.1007/s00170-018-2028-4

Jadam, T., Rakesh, M., \& Datta, S. (2020). Machinability of Ti-6Al-4V Superalloy: Performance of Dry Cutting and Nanofluid MQL (MWCNT-Added Rice Bran Oil). Arabian Journal for Science and Engineering, 45(7), 5673-5695. Advance online publication. doi:10.1007/s13369-020-04516-4

Jaffery, S. H. I., \& Mativenga, P. T. (2012). Wear mechanisms analysis for turning Ti-6Al-4V towards the development of suitable tool coatings. International Journal of Advanced Manufacturing Technology, 58(5-8), 479-493. doi:10.1007/s00170-011-3427-y

Jayal, A. D., Badurdeen, F., Dillon, O. W. J. Jr, \& Jawahir, I. S. (2010). Sustainable manufacturing: Modeling and optimization challenges at the product, process and system levels. CIRP Journal of Manufacturing Science and Technology, 2(3), 144-152. doi:10.1016/j.cirpj.2010.03.006

Khan, Mia, \& Dhar. (2017). High-pressure coolant on flank and rake surfaces of tool in turning of Ti-6Al-4V: investigations on forces, temperature, and chips. International Journal of Advance Manufacture Technology, 90, 1977-1991. DOI .10.1007/s00170-016-9511-6

Li, G., Li, N., Wen, C., \& Ding, S. (2018). Investigation andmodeling of flank wear process of different PCD tools in cutting titanium alloy Ti6Al4V. International Journal of Advanced Manufacturing Technology, 95(1), 719-733. doi:10.1007/s00170-017-1222-0

Lin, H., Wang, C., Yuan, Y., Chen, Z., Wang, Q., \& Xiong, W. (2015). Toolwear in Ti-6Al-4V alloy turning under oils on water cooling comparing with cryogenic air mixed with minimal quantity lubrication. International Journal of Advanced Manufacturing Technology, 81(1), 87-101. doi:10.1007/s00170-015-7062-x 
Liu, N., Zheng, C., Xiang, D., Huang, H., \& Wang, J. (2019). Effect of cutting parameters on tool wear under minimum quantity cooling lubrication (MQCL) conditions. International Journal of Advanced Manufacturing Technology, 105(1-4), 515-529. doi:10.1007/s00170-019-04259-z

Muthukrishnan, N., \& Davim, P. (2011). Influence of Coolant in Machinability of Titanium Alloy. Journal of Surface Engineered Materials and Advanced Technology, 1(01), 9-14. doi:10.4236/jsemat.2011.11002

Najiha, M. S., Rahman, M. M., \& Yusoff, A. R. (2016). Environmental impacts and hazards associated with metal working fluids and recent advances in the sustainable systems: A review. Renewable \& Sustainable Energy Reviews, 60, 1008-1031. doi:10.1016/j.rser.2016.01.065

Nandy, K.A., Gowrishankar, C.M., \& Paul, S. (2009). Some studies on high-pressure cooling in turning of Ti-6Al-4V. International Journal of Machine Tools \& Manufacture, 49, 182-198. doi:10..10.1016/ j.ijmachtools.2008.08.008

Pervaiz, S., Rashid, A., Deiab, I., \& Nicolescu, C. M. (2016). An experimental investigation on effect of minimum quantity cooling lubrication (MQCL) in machining titanium alloy (Ti6Al4V). International Journal of Advanced Manufacturing Technology, 87(5-8), 1371-1386. doi:10.1007/s00170-016-8969-6

Rahman Rashid, R. A., Sun, S., Wang, G., \& Dargusch, M. S. (2012). An investigation of cutting forces and cutting temperatures during laser-assisted machining of the Ti-6Cr-5Mo-5V-4Al beta titanium alloy. International Journal of Machine Tools \& Manufacture, 63, 58-69. doi:10.1016/j.jimachtools.2012.06.004

Rifat, M., Rahman, H., \& Das, D. (2017). A Review on Application of Nanofluid MQL in Machining. AIP Conference Proceedings. doi:10.1063/1.5018533

Rosemar, B. (2013). Tool life and wear mechanisms in high speedmachining of Ti-6Al-4 Valloy with PCD tools under various coolant pressures. Journal of Materials Processing Technology, 213(8), 1459-1464. doi:10.1016/j. jmatprotec.2013.03.008

Sharif, S., \& Rahim, E. A. (2007). Performance of coated-and uncoatedcarbide tools when drilling titanium alloyTi-6A14V. Journal of Materials Processing Technology, 185(1), 72-76. doi:10.1016/j.jmatprotec.2006.03.142

Singh, T., Singh, P., Dureja, J. S., Dogra, M., Singh, H., \& Bhatti, M. S. (2016). A review of near dry machining/ minimum quantity lubrication machining of difficult to machine alloys. International Journal of Machining and Machinability of Materials, 18(3), 213-251. doi:10.1504/IJMMM.2016.076276

Xu, J., Liu, Z., An, Q., \& Chen, M. (2012). Wear mechanism of highspeed turning Ti-6Al-4V with TiAlN and AlTiN coated tools in dry and MQL conditions. Advanced Materials Research, 497, 30-34. doi:10.4028/www. scientific.net/AMR.497.30

Zelinka, D., \& Amadei, B. (2019). Systems Approach for Modeling Interactions Among the Sustainable Development Goals Part 1: Cross-Impact Network Analysis. International Journal of System Dynamics Applications, 8(1), 23-40. doi:10.4018/IJSDA.2019010102 